\title{
POR UM LEITOR COM DÚVIDAS - NOTAS SOBRE ARTE E FASCISMO, DE ANATOL ROSENFELD
}

http://dx.doi.org/10.11606/issn.2237-1184.v0i24p147-158

\author{
Jaime Ginzburg \\ Universidade de Paulo (USP)
}

\section{RESUMO}

O ensaio Arte e fascismo, de Anatol Rosenfeld, está diretamente ligado à Segunda Guerra Mundial e a seu impacto cultural. Esse ensaio apresenta dúvidas com relação ao valor estético atribuído a obras de arte criadas por pessoas que defenderam o fascismo. Os argumentos abrem espaço para antagonismos. Arte $e$ fascismo é um texto no qual as dúvidas são muito importantes, para lidar com dificuldades éticas referentes a valores estéticos. Diante desses antagonismos, quando uma reflexão crítica não pode atingir nenhuma síntese, o leitor poderia perceber que é necessário enfatizar o quanto as dúvidas são importantes para pensar sobre desafios éticos e estéticos.

\section{ABSTRACT}

Anatol Rosenfeld's essay Arte e fascismo (Art and fascism) is directly related to World War II and its cultural impact. The essay brings up doubts regarding aesthetic value attributed to works of art created by people who defended fascism. The arguments open space to antagonisms. Arte e fascismo is a text in which doubts are very important to deal with ethical difficulties regarding aesthetic values. In face of those antagonisms, when a critical reflection cannot achieve any synthesis, the reader might realize it is necessary to emphasize how doubts are important in order to think about ethical and aesthetical challenges.
PALAVRAS-CHAVE:

Arte.

Fascismo.

Antagonismo.

Ensaio.

Anatol Rosenfeld.

KEYWORDS:

Art.

Fascism

Antagonism.

Essay.

Anatol Rosenfeld. 
que ocorre quando gostamos de uma obra de arte, e em um dia, descobrimos que o artista que a criou defende um regime totalitário? Deve essa descoberta modificar o juízo de valor estético sobre a obra? Deve a arte ser considerada inteiramente independente das percepções políticas de seu criador? Essas dúvidas podem surgir quando lemos Arte e fascismo, de Anatol Rosenfeld ${ }^{1}$.

Publicado há 70 anos, em 21 de fevereiro de 1947, no Jornal de São Paulo, esse ensaio de Anatol Rosenfeld exige atenção no momento presente. Ele faz parte de um conjunto de textos produzidos por intelectuais, após a Segunda Guerra Mundial, em que reflexões procuram avaliar e delimitar funções dos trabalhos intelectuais e de obras artísticas para a sociedade.

Depois de milênios em que a civilização ocidental produziu séries de trabalhos intelectuais e obras de arte caracterizados como obrasprimas, e atribuiu estatuto de gênios a pensadores e artistas, foi necessário lidar com o fato de que nada disso foi capaz de impedir as catástrofes das duas grandes guerras. Nenhum saber universitário impediu que fossem construídos campos de concentração nazistas.

Diante disso, o que esperar da vida acadêmica? Como avaliar a importância das obras de arte? A noção de genialidade se mostrou como um atributo que não se associa necessariamente a parâmetros éticos. No caso específico da Alemanha, país que contribuiu de modo decisivo para a expansão do alcance da filosofia, a tradição intelectual não impediu que prosperasse uma política voltada para exclusão, violência e desumanização.

O ensaio Arte e fascismo expressa um confronto com o momento pós-guerra, em que o trauma coletivo impregnava sociedades em diversos países. Anatol Rosenfeld publica o texto em um jornal, em um país cuja vida acadêmica ainda estava em construção. Felizmente, a Editora Perspectiva, a Edusp e a Editora da Unicamp integraram o trabalho ao volume Texto/contexto II, em 1993, permitindo o acesso ao ensaio. As editoras merecem reconhecimento, pela importante iniciativa.

Embora breve, o texto de Rosenfeld encerra um dos casos mais extraordinários de prática de uma escrita ensaística já realizados no país. Ele é composto de três partes, indicadas com algarismos romanos.

${ }^{1}$ ROSENFELD, Anatol. Arte e fascismo. In: Texto/contexto II. São Paulo:Edusp/Perspectiva/Ed. Unicamp, 
Como hipótese de leitura do texto, cabe propor uma perspectiva específica de abordagem, que leve em conta o período pós-guerra e desafios intelectuais desse período.

O ensaio propicia uma valorização do leitor que tem dúvidas a respeito dos textos que lê. Diferentemente de outras perspectivas de teoria e crítica literária em circulação no Brasil nos anos 40 , voltadas para o conhecimento sintético e o julgamento conclusivo de obras, o ensaio de Rosenfeld mantém um espaço aberto para a incerteza e a indeterminação.

A principal motivação para o questionamento consiste na articulação proposta no título. É possível falar em arte fascista? Mais especificamente, o que acontece quando descobrimos que um artista que respeitamos deixou evidências de simpatizar com valores próprios do fascismo?

Seria a arte de um fascista condicionada pela ideologia do artista e, portanto, caracterizada por desumanização? Ou seria a arte independente da vida do artista, sustentando seu valor em si mesma, alheia às orientações ideológicas de seu criador?

No mesmo ano de 1947, Anatol Rosenfeld publicou A crise da democracia. Nesse texto, o autor caracteriza um "estado de fascismo latente" em seu tempo. Ele analisa a "atração enorme que o fascismo exerce" e a presença do fascismo latente em diversos países². É possível perceber, articulando A crise da democracia e Arte e fascismo, que as reflexões sobre arte no segundo texto estão em consonância com a análise política do primeiro. Se isso é pertinente, é necessário entender que, no título Arte e fascismo, esse regime é visto como uma presença nas forças históricas, em um contexto de democracias formais em que práticas democráticas não são cultivadas como seria esperado.

A reflexão sobre os artistas, nesse sentido, ultrapassa a fronteira delimitada por artistas conhecidos, e ganha força como teorização. As dúvidas formuladas em Arte e fascismo de modo algum se esgotaram em 1947. Ao contrário, práticas repressoras no contexto da produção cultural, consistentes com ideias fascistas, têm sido correntes, no Brasil e em outros países.

É possível elaborar a hipótese de que, mesmo escrevendo dois anos após o final da Segunda Guerra, o autor do ensaio não tenha segurança para assumir que o mundo teria, de fato e suficientemente, se transformado a ponto de evitar o retorno da destruição. "Seu mundo é a realidade do fascismo totalitário. (...) Somente o conteúdo materialista bruto da liberdade nega toda repressão"3. Em um contexto de ruínas, em que a memória corporal da destruição é muito intensa, o futuro, quanto à diminuição ou ausência de repressão, é incerto. A crise da democracia

\footnotetext{
${ }^{2}$ ROSENFELD, Anatol. A crise da democracia. In: 2011. p.193.

${ }^{3}$ MARCUSE, Herbert. Tecnologia, guerra e fascismo. São Paulo: Ed. UNESP, 1999. p.271-272.
} 
apresenta com clareza e precisão suas posições sobre "a desumanização do mundo" em seu tempo ${ }^{4}$. Ele afirma: "É pura demagogia querer conversar esse estado de coisas para conservar uma liberdade que há muito não existe. (...) Terminou a época que considerava o Estado uma espécie de guarda-noturno que, de quando em vez, apita nas esquinas e, de resto, lava as mãos (...) Eis porque a democracia puramente formal e política tornou-se obsoleta, fachada oca" ${ }^{5}$.

É no limiar entre as opções binárias que o ensaio se desenvolve, sem desenvolver uma racionalidade sintética, e sem apressar uma conclusão definitiva. A argumentação se estabelece em uma linha de dúvida. Se a divisão em três partes pode sugerir um movimento dialético (tese, antítese e síntese), a dinâmica do pensamento contraria essa sugestão.

Arte e fascismo é um texto que pode ser compreendido à luz de $O$ ensaio como forma, de Theodor Adorno. Cabe considerar o seguinte:

O ensaio reflete o amado e o odiado (...) o ensaio se aproxima de uma certa autonomia estética ${ }^{6}$.

Mesmo sem dizer isso expressamente, o ensaio se conscientiza quanto à não-identidade; radical no não-radicalismo, na abstenção diante de qualquer redução a um princípio, no gesto de acentuar o parcial diante do total, no caráter fragmentário. ${ }^{7}$

A sua fraqueza testemunha a própria não-identidade, que ele deve expressar (...) Naquilo que é enfaticamente ensaio, o pensamento se libera da ideia tradicional de verdade. (...) ele leva mais a sério a maneira de expor do que aqueles modos de proceder que separam o método do assunto e são indiferentes à exposição do seu conteúdo objetivado. (...) $\mathrm{O}$ ensaio exige não menos, porém mais que o procedimento por definições, interação dos seus conceitos no processo da experiência espiritual. Nesta, eles não constituem nenhuma continuidade operacional e o pensamento não avança unilateralmente (...) A configuração é um campo de força, assim como, sob o olhar do ensaio, toda formação espiritual precisa transformar-se num campo de forças.

$O$ ensaio desafia suavemente o ideal da percepção clara e distinta e também o da certeza livre de dúvida ${ }^{8}$.

Arte e fascismo se caracteriza por um distanciamento com relação a concepções tradicionais de verdade. O texto não propõe uma atitude conclusiva com relação às reflexões que apresenta. Ao contrário, o valor do ensaio, fundamentado na sua especificidade e singularidade, está associado ao movimento de apresentação e articulação de ideias. O título pode ser interpretado de diversas maneiras, a partir da leitura. Existem frases que defendem a separação entre arte e fascismo, propondo a

\footnotetext{
${ }^{4}$ ROSENFELD, Anatol. A crise da democracia. In: 2011. p. 189.

${ }^{5}$ Idem, p. 189-190.

${ }^{6}$ ADORNO, Theodor. O ensaio como forma. In:

${ }^{7}$ Idem, p.173.

${ }^{8}$ Idem, p. 175-177. Preconceito, racismo e política. São Paulo: Perspectiva,
} 
autonomia da arte e a independência entre vida e obra. Aparecem também frases que reconhecem a integralidade do artista e do intelectual, de modo que não haveria separação entre seus processos de pensamento e suas posições políticas. Anatol Rosenfeld não assume uma unilateralidade em sua enunciação. Ele se move entre diferentes pontos de vista, como se estabelecesse o antagonismo como uma categoria decisiva para elaborar sua reflexão.

Esse princípio dissociativo impregna a epistemologia que fundamenta o ensaio. A concepção de conhecimento de Arte e fascismo está voltada para a afirmação da dúvida. A incerteza é um dos elementos principais da dinâmica de construção do texto. O leitor, ao acompanhar o sujeito da enunciação em seus movimentos, atravessa uma variação de distância com relação ao objeto. Algumas linhas podem dar a impressão de um argumento consolidado, que atribuiria uma delimitação clara do assunto. No entanto, irrompem deslocamentos de ângulo de reflexão, que levam a testar a pertinência argumentativa de diferentes termos. Com essas irrupções, o leitor é motivado a duvidar da segurança dos argumentos expostos.

Com isso, ao invés de definir uma posição quanto a relações entre arte e fascismo, o ensaio intensifica à máxima potência o impasse com relação ao valor estético das obras de arte. Com uma reflexão que não se desenvolve em uma única direção, o espaço do ensaio se caracteriza como uma arena, em que diferentes forças históricas estão em confronto. O impacto da Segunda Guerra Mundial leva a rejeitar o fascismo em todas as suas expressões. A consideração de juízos estéticos positivos, atribuídos, antes da guerra, a certos artistas que aderiram ao fascismo, leva a ponderar a respeito da continuidade da validação desses juízos. $O$ antagonismo histórico expresso no texto se constitui como antagonismo formal. Cada ideia que parece conclusiva, ainda que por um momento, não chega ao final como síntese entre os diferentes posicionamentos.

E se cobrássemos do ensaio, como leitores, uma posição firme? Em termos políticos, um leitor em 2017 poderia esperar, talvez, uma posição radicalmente contrária ao fascismo. E se esperássemos, como quem espera preencher uma lacuna, uma síntese conclusiva para a reflexão? Teríamos então algumas possibilidades de conclusão. Entre elas, poderiam hipoteticamente ser esperadas pelos leitores as seguintes: (a) a arte é autônoma, inteiramente independente de posições políticas de seu criador, e portanto independente de que o criador seja fascista; (b) a arte é uma parte integrante da produção de pensamentos, imagens, ideias e conceitos de seu criador; por mais que esse criador se transforme ao longo da vida, a adesão ao fascismo, quando ocorre, deve concentrar nossa atenção; mesmo que a arte não pareça conter traços de fascismo, o seu valor é condicionado pela posição política do criador; (c) como os artistas podem ser considerados, de acordo com o texto, figuras caracterizadas de modo irregular com relação a padrões sociais, não seria 
surpreendente que, em uma perturbação mental, um artista defendesse o fascismo; (d) a arte é superior à negatividade humana e se associa à esperança, portanto, ela não deve, independentemente de quem seja o artista, ser considerada de modo negativo. A posição (a) poderia ser contestada por intelectuais que consideram questões políticas ao avaliar obras de arte; a alternativa (b) poderia ser contestada por leitores que admiram artistas que defenderam publicamente o fascismo; 0 posicionamento (c) poderia ser contestado por aqueles que não aceitam a imagem do artista como uma figura negativa para a sociedade; a posição $(d)$ poderia ser considerada idealista, e confrontada com as expressões históricas de interesses destrutivos.

Considerar essa pluralidade, em termos hipotéticos, é um resultado da eficácia de procedimentos formais do ensaio. É como se o intelectual estivesse cindido entre, pelo menos, duas formas de pensamento: a rejeição do fascismo em todas as suas expressões, e o respeito à arte em todas as suas expressões. Em 1947, diante da catástrofe, as duas formas parecem necessárias para resguardar a afirmação de valores humanos em um tempo de incertezas. A ideia de uma arte de fascistas, ou mesmo de uma arte fascista, configura um paradoxo, que somente poderia ser desfeito com o sacrifício de uma das duas formas de pensamento.

Em Arte e fascismo, o pensamento não se subordina a essa exigência de sacrifício. Ele se movimenta, de acordo com um percurso antagônico, entre a hipótese de admitir a arte de um criador fascista, que garantiria o respeito a toda a arte, e a hipótese de eliminar o valor atribuído à arte de criadores fascistas, que representaria uma rejeição sem exceções ao fascismo.

A ideia aqui não é de que Anatol Rosenfeld, apesar de antagonismos internos na argumentação, publicou o ensaio. Ao contrário, o autor o publicou de um modo que fosse incontornável reconhecê-los. Como se pudéssemos, enquanto leitores, em hipótese, esperar um momento conciliador diante do inconciliável, lemos o ensaio atravessado pelo impacto da catástrofe. A conciliação não pode aparecer no ensaio, uma vez que as condições para evitar a repetição da catástrofe não estão eliminadas da História.

O procedimento negativo com relação à constituição de um saber permite a Rosenfeld estimular a dúvida, como forma capaz de manifestar a contradição objetiva sobre a qual se debruça. Em um tempo em que artistas fascistas são reconhecidos, é apresentada por Rosenfeld uma dúvida sobre a legitimidade desse reconhecimento.

Para ele, essa legitimidade constitui uma contradição própria do objeto de reflexão. Como amar um poema de Ezra Pound, sem rejeitar o fascismo? O horror, resultante da percepção de que Pound seja artista e também fascista, é importante para constituir a dialética negativa do ensaio. Não cabe ao ensaísta converter uma contradição objetiva em uma 
definição totalizante. O pensamento abstrato não deve amenizar aquilo que, concretamente, causa inquietação, pois a amenização seria um falseamento, inadmissível para um momento em que o impacto da guerra condiciona a vida intelectual.

A primeira parte de Arte e fascismo faz referência a um estranhamento, resultante da caracterização de Knut Hamsun como "grande artista" 9 e também como fascista. Para Rosenfeld, há algo perturbador na combinação entre as duas características, pois seria esperado de um artista que não contrariasse ideais caros à humanidade. O ensaísta opina que em ciências, como a física, é possível que a competência seja conciliada com um perfil "desprezível" ${ }^{10}$. São os campos das artes e das ciências humanas que preocupam. Arte e fascismo constitui um cruzamento entre ética e epistemologia, apontando para um risco de aporia, estabelecido pela possibilidade de que pesquisas em áreas voltadas para o estudo do ser humano estejam dedicadas à destruição da humanidade. Nessa perspectiva, o horizonte político de cada intelectual estaria diretamente ligado ao modo como ele elabora e desenvolve conceitos.

Rosenfeld discute a autonomia da arte, especulando a respeito da possibilidade de separação entre política e arte, e da ideia de que a realização de um ideal estético não dependeria de conteúdos ideológicos. O ensaísta define a arte como um "símbolo da perfeição humana" 11 em que forças contrárias se equilibram. Em seguida, é discutida a fundamentação do nazi fascismo, com uma crítica ao capitalismo, ao poder tirânico e à aniquilação da justiça. No final da parte I, Rosenfeld elabora a perspectiva de que possa haver divergência entre a obra e seu criador.

Na segunda parte, o autor desenvolve, a partir da leitura de Ernst Krestschmeer, uma reflexão sobre artistas caracterizados de maneira negativa. Uma longa lista de exemplos delimitaria uma associação entre doença e arte. Na relação de elementos considerados negativos, aparecem epilepsia, narcofilia, neurose e hipocondria. Aparece também, em abordagem conservadora comum na época, e em destaque, a homossexualidade. Para um olhar contemporâneo, a parte II consiste em uma manifestação de um conjunto de preconceitos. A presença de Goethe, Baudelaire, Poe, Wilde e Flaubert, entre outros, tem um efeito desconcertante, como se a literatura canônica ocidental estivesse atravessada por figuras perturbadas. Essa abordagem redutora teria como objetivo propor a compreensão do intelectual e do artista como figuras imprevisíveis, instáveis e acometidos por comportamentos reprováveis. A vantagem metodológica disso consiste em guardar uma

\footnotetext{
${ }^{9}$ ROSENFELD, Anatol. Arte e fascismo. In: 1993. p.189.

${ }^{10}$ Idem, p. 190.

${ }^{11}$ Idem, p. 191 Texto/contexto II. São Paulo: Edusp/Perspectiva/Ed. Unicamp,
} 
margem de justificação: se por hipótese intelectuais e artistas fossem descontrolados e moralmente condenáveis, não haveria dificuldade em supor que seriam capazes de vivenciar uma cisão radical entre sua produção artística e suas ideias políticas. A argumentação, no entanto, não chega a sugerir, explicitamente, que Dante, Mozart e Kierkegaard, entre outros citados, seriam capazes de aderir a ideias próximas do nazismo. A exemplificação, nessa passagem, não corresponde aos exemplos preocupantes de artistas com abertura para ideias voltadas para a destruição dos homens.

Se o texto seguisse um raciocínio dialético, a terceira parte poderia, em hipótese, achar uma conciliação entre a ideia da separação entre arte e política e a proposição de que artistas e intelectuais podem ser doentes e alheios a normas sociais. Se essa conciliação ocorresse, ela consistiria em justificar os casos de adesão ao nazismo com diagnósticos de doença mental. Assim, seguindo essa hipótese, não seria apontada uma contradição entre defender o nazismo e realizar ideais estéticos. A razão para não ser apontada não é de que essa caracterização atende critérios lógicos de pensamento mas, ao contrário, é de que, se existem perturbações mentais graves, não haveria capacidade racional para sustentar, como juízo, a decisão voluntária de defender o nazismo.

No entanto, a terceira parte não cumpre essa função conciliadora. Ao contrário, Rosenfeld acentua o fato de que a relação entre "a obra e o seu criador, embora muito íntima, não é simples e direta, mas contraditória e ambígua" 12 . Admitindo a complexidade do objeto de sua reflexão, o ensaísta descarta a perspectiva de que a arte expressasse o universo psíquico de um artista sem uma mediação, um processo caracterizado por articular ou organizar esteticamente os elementos de uma obra.

É na terceira parte que a convicção ética de Rosenfeld é expressa de maneira mais convicta e firme, no seguinte trecho:

Temos que reconhecer, pois, que, dentro da ordem estética, não pode sobreviver o anti-humano, a não ser como representação justamente do retrógado e do desprezível. A própria tentativa de glorificação de ideias fascistas forçaria o artista a transformá-las, a torná-las simpáticas e humanas, a cercá-las de graça e beleza, a elevá-las de forma que se tornariam a sua própria contradição" 13 .

A escolha do verbo sobreviver remonta ao passado recente, com a derrota do nazi fascismo na Segunda Guerra Mundial. A palavra evoca os conflitos que levaram à morte milhões de pessoas, e remete aos que não pereceram, nem mesmo após anos em campos de concentração. No trecho, a expressão "não pode sobreviver", em perspectiva avessa, se

\footnotetext{
${ }^{12}$ Idem, p. 196.

${ }^{13}$ Idem, p. 197.

154 | D O S S I Ê : LEITORES E LEITURAS NA CONTEMPORANEIDADE
} 
refere à necessidade de não repetir, não permitir que volte, na vida, nas ideias e nas artes, a haver espaço para a dominação social por parte do movimento contrário à sobrevivência da humanidade, proposto por líderes fascistas e, em particular, pelo regime de Hitler na Alemanha.

O verbo forçar, por sua vez, tem como premissa uma imagem genérica dos artistas, de acordo com a qual para glorificar artisticamente a desumanização seria necessário atribuir beleza a ela, o que resultaria em uma contradição. A beleza, nesse sentido, estaria, em princípio, associada à valorização da humanidade.

O final do ensaio apresenta uma imagem religiosa: "A arte realiza milagres"14. Dedicado ao caso de Ezra Pound, Rosenfeld propõe que a obra teria um papel de "filtro", de modo que a arte não expressaria, nesse caso, as ideias do poeta favoráveis ao fascismo. Com isso, Rosenfeld conclui o ensaio com uma metáfora - "até o lodo reflete as estrelas". A imagem sugere que a realização estética de alto nível, representada pelas estrelas, pode surgir no interior de um pensamento impregnado pela negatividade (o "lodo") de uma perspectiva política que defende a destruição.

Mesmo observando que o ensaio inclui afirmações que parecem ser contundentes e conclusivas, e sequências de ideias que parecem contribuir para argumentos gerais, existe nesse texto um conjunto de movimentos que afasta a percepção de que, em 1947, Rosenfeld tenha chegado a uma percepção conclusiva sobre o assunto.

Gostaria de assinalar alguns elementos que despertam interesse, no que se refere a esse conjunto. Sem ter como objetivo analisar todos os argumentos do ensaio, cabe observar alguns deslocamentos na formulação de argumentos.

(1) p. 190. É afirmado que "grandes artistas são conservadores".

(2) p.190. A proposição (1) é contrariada pela defesa de que não seria esperado encontrar um "espírito essencialmente ilegítimo" em grandes artistas.

(3) p. 191. É afirmado que o "esteticamente perfeito não tem nenhuma relação com aquilo que nós chamamos legítimo na história políticosocial".

(4) p.191. Rosenfeld contraria o argumento (3) dizendo: "Esse argumento não satisfaz, porém, inteiramente".

(5) p.191. É definido que a arte é um símbolo "da perfeição humana, de um estado de graça".

(6) p.192. É afirmado que a arte "é essencialmente adversa a qualquer movimento político que se empenha numa direção oposta a esse ideal",

\footnotetext{
${ }^{14}$ Idem, p. 198.
} 
o ideal de uma "imensa esperança, do anseio de uma infinita aproximação".

(7)p.193. É definido que "arte e fascismo se encontram em campos opostos".

(8)p.193. É afirmado que existem "verdadeiras obras de arte criadas por adeptos do fascismo", contrariando o argumento (6).

(9)p.194. É proposto que a "obra de arte tem sua própria autonomia e uma "vida" diferente do seu autor", reforçando o argumento (6) e relativizando o argumento (8).

(10)p.194. Rosenfeld fala em "estruturas psíquicas patológicas" dos artistas, e constitui, na p.195, uma listagem de artistas e intelectuais que seriam doentes ou capazes de condutas socialmente inaceitáveis.

(11)p.196. Rosenfeld propõe que a relação entre obra e criador é "contraditória e ambígua". Com isso, se for feita a releitura dos argumentos (3), (6), (7), (9) e (10), a impressão é de que o ensaísta suscita dúvidas quanto à ideia de atribuir valor negativo a uma obra de arte em razão de características do artista.

(12)p.196. O ensaísta afirma que conflitos são apresentados em obras de maneira articulada "ou esteticamente organizada", desautorizando a defesa da eficácia da aplicação irrefletida dos termos do argumento (10), ligados a doenças, no julgamento de obras.

(13)p.197. O autor defende que "dentro da ordem estética, não pode sobreviver o anti-humano", ideia que remonta ao argumento (5) e suscita dúvidas quanto à significação do argumento (8).

(14)p.198. É definido que "a obra de arte tem uma essência que independe das contingências biográficas do seu criador", reforçando o argumento (3), que já tinha sido contrariado pelo argumento (4). O argumento (11) apontava para a complexidade da relação entre obra e criador; este argumento (14) parece desconsiderar essa complexidade, em favor de uma posição bem definida.

(15)p.198. Rosenfeld identifica Pound, "o poeta", com Pound, "o homem". Essa identificação permite validar o argumento (8) com um exemplo conhecido. No entanto, ela torna difícil sustentar os argumentos que consolidariam a ideia de uma separação entre vida e obra, como (7), (9) e (14).

(16)p.198. A imagem de que a arte "realiza milagres" reforça a imagem do "estado de graça", no argumento (5).

O direcionamento da reflexão assumido pelos argumentos (8) e (15) é incompatível com a linha de pensamento exposta nos argumentos (7), (9) e (14). Além disso, (15) e (16) não operam sínteses das linhas de argumentação. A construção do texto permite colocar à prova 
diferentes formas de entender o problema, sem estabelecer nenhuma delas como suficientemente segura.

A escolha da metáfora religiosa no final contraria a expectativa de um desfecho capaz de expor uma escolha consciente de Rosenfeld entre, por um lado, a conjunção entre valor de obra e perfil do seu criador ou, por outro lado, a separação em favor da autonomia da obra e de um julgamento do valor estético independente das ideias políticas do criador. Sem essa escolha, a imagem do milagre religioso sugere que, ao final, não escaparíamos inteiramente daquilo que é, para Rosenfeld e para os leitores de seu ensaio, improvável e eticamente inaceitável - o fato de que a defesa da autonomia da arte permitiria admitir, no campo intelectual, a criação de beleza por parte de um fascista. A palavra "milagre" se reveste, nesse caso, de negatividade constitutiva, como se fosse uma imagem construída com ironia romântica, e evoca um fracasso. Dois anos depois do fim da Segunda Guerra, atribuir beleza a uma arte criada por um fascista não consiste em um "milagre" como experiência sublime, de elevação humana. Pelo contrário, trata-se, para utilizar os termos da última frase, de acentuar a força do "lodo", e de duvidar sobre a possibilidade de as estrelas serem visíveis nesse lodo.

Se a arte é símbolo da "perfeição humana, de um estado de graça", e se existe um ideal de "imensa esperança", faz sentido a afirmação de que "dentro da ordem estética, não pode sobreviver o anti-humano". Essa caracterização positiva da arte agrega aos elementos estéticos componentes ligados a uma percepção otimista do futuro, com um ideal de eliminação da precariedade das condições concretas de existência. Para o ano de 1947, os horizontes de expectativa para a leitura desse texto estão associados às ruínas do ocidente devastado pela guerra, ao luto em processo pelos milhões de mortos, e à incerteza quanto à redistribuição das forças políticas. Isso quer dizer que as imagens positivas significam muito diante do impacto de um trauma coletivo. No entanto, não há garantias de que esse otimismo seja sustentável, de que essa esperança leve à superação concreta de dificuldades, ou de que o anti-humano desapareça. Sem essas garantias, o texto de Rosenfeld dialoga com o seu tempo, subordinando a reflexão teórica a uma perspectiva ética, e incorporando um estado de incerteza que impregnou a época.

É admirável a maneira como Arte e fascismo fomenta dúvidas. O argumento (2) contraria o argumento (1). O mesmo ocorre com (4) com relação a (3). O argumento (8) é relativizado por (9) e (13), assim como (10) por (11) e (12), e por sua vez (11) é relativizado por (14). Sem conciliar os pontos de vista apresentados, sem finalizar com uma síntese capaz de estabelecer uma conclusão para os questionamentos, o ensaio se movimenta entre possibilidades de pensamento. Com isso, ele dramatiza um debate que deveria estar ocorrendo na sociedade, com 
relação às formas de atribuir significação a obras de arte e a trabalhos intelectuais.

A forma do ensaio, em seu movimento, tem a eficácia de uma apresentação teatral em uma arena: as afirmações são expostas à crítica, as definições se mostram insuficientes, a atribuição de significado às assertivas pode variar à medida que o leitor percorre o texto e encontra ponderações. Arte e fascismo promove a dúvida como competência de leitura. Por essa razão, se afasta do autoritarismo presente em manifestações fascistas. Uma concepção de escrita que prioriza a dúvida em detrimento da unidade sintética não pode ser apropriada pelo fascismo ${ }^{15}$. No ensaio existe um traço melancólico, que expressa perdas não superadas. Entre elas, está a perda da confiança na autonomia da arte, em face da catástrofe. Essa desconfiança converge, para lembrar de Walter Benjamin, com a "desconfiança acerca do destino da literatura, desconfiança acerca do destino da liberdade, desconfiança acerca do destino da humanidade europeia, e principalmente, desconfiança, desconfiança e desconfiança com relação a qualquer forma de entendimento mútuo: entre as classes, entre os povos, entre os indivíduos"16. Não há como reparar essas perdas de confiança, e por isso é fundamental admitir e valorizar a dúvida, como forma não sintética de elaboração de conhecimento e como procedimento de articulação interna da escrita ensaística.

Em A crise da democracia, o discurso crítico de Rosenfeld se volta contra a ilusão de que a democracia tenha sido concretizada de modo suficiente e justo, após a Segunda Guerra Mundial. É um texto que evita qualquer idealização. De dentro da incerteza sobre o futuro, o ensaísta elabora suas percepções. A sua atualidade, diante do Brasil no presente, é espantosa. Arte e fascismo, similarmente, aborda o juízo estético através da reflexão sobre critérios incertos. As dúvidas que ele formulou sobre as artes constituem a melhor expressão possível do antagonismo entre o intelectual e seu tempo de fascismo latente, antagonismo necessário e certeiro. Elaborar essas dúvidas pode, em hipótese, ser suficiente para afirmar que a arte não deve ser considerada inteiramente independente das percepções políticas de seu criador, se essas percepções contrariarem a nossa própria sobrevivência.

\footnotetext{
${ }^{15}$ BENJAMIN, Walter. Magia e técnica, arte e política. São Paulo: Brasiliense, 1985. p.166.

${ }^{16}$ Idem, p. 34.
} 